\title{
Correction to: Multi-sensor temporal assessment of tropospheric nitrogen dioxide column densities over Pakistan
}

\author{
Rabbia Murtaza ${ }^{1,2} \cdot{\text { Muhammad Fahim } \text { Khokhar }^{1} \cdot \text { Asma Noreen }^{1} \cdot \text { Salman Atif }}^{3} \cdot$ Khalid Rehman Hakeem $^{4}$
}

Published online: 3 March 2018

(C) Springer-Verlag GmbH Germany, part of Springer Nature 2018

\section{Correction to: Environ Sci Pollut Res} https://doi.org/10.1007/s11356-017-1176-7

The present address of Rabbia Murtaza is shown in this paper.

The online version of the original article can be found at https://doi.org/ 10.1007/s11356-017-1176-7

\footnotetext{
Muhammad Fahim Khokhar fahim.khokhar@iese.nust.edu.pk

$\triangle$ Khalid Rehman Hakeem kur.hakeem@gmail.com; khakim@kau.edu.sa

1 Institute of Environmental Sciences and Engineering, National University of Sciences and Technology, H-12, Islamabad 44000, Pakistan

2 Present address: Center for Climate Research and Development (CCRD), COMSATS, Institute of Information technology (CIIT), Islamabad 44000, Pakistan

3 Institute of Geographical Information System, National University of Sciences and Technology, H-12, Islamabad 44000, Pakistan

4 Department of Biological Sciences, Faculty of Science, King Abdulaziz University, Jeddah 21589, Saudi Arabia
} 